\title{
Influence of spermatozoal lipidomic profile on the cryoresistance of frozen spermatozoa from stallions
}

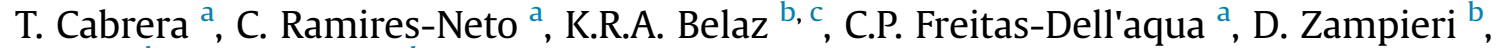 \\ A. Tata ${ }^{\text {b }}$, M.N. Eberlin ${ }^{\text {b }}$, M.A. Alvarenga ${ }^{\text {a }}$, F.F. Souza ${ }^{\text {a, * }}$ \\ a Department of Animal Reproduction and Veterinary Radiology, Faculty of Veterinary Medicine, FMVZ, São Paulo State University (UNESP), Botucatu, Brazil \\ b ThoMSon Mass Spectrometry Laboratory, Institute of Chemistry, University of Campinas (UNICAMP), Campinas, SP, Brazil \\ ${ }^{\mathrm{c}}$ Institute of Chemistry, Federal University of Uberlândia (UFU), Uberlândia, MG, Brazil
}

\section{A R T I C L E I N F O}

\section{Article history:}

Received 21 June 2017

Received in revised form

21 November 2017

Accepted 21 November 2017

Available online 26 November 2017

\section{Keywords:}

Equine

Lipid-profile

Mass spectrometry

Freeze-semen

Spermatozoa

\begin{abstract}
A B S T R A C T
The membrane of spermatozoa, which contributes to cellular cryoresistance, contains numerous lipids with a composition that directly affects membrane fluidity and the fertilization process. In light of variations in the degree of sensitivity in equine seminal freezing, this study aimed to correlate equine semen lipids with post-thawing characteristics of spermatozoa. We used ejaculates from 34 stallions, which were evaluated (total motility $\geq 60 \%$ ), frozen and thawed and reevaluated for motility of spermatozoa, membrane integrity and lipid peroxidation. Lipid extraction of the fresh semen samples was performed by liquid-liquid extraction, and fingerprinting lipid analysis was conducted by matrix-assisted laser desorption/ionization mass spectrometry (MALDI-MS). Based on the characteristics of spermatozoa after thawing, the animals could be separated into two groups: resistant (Good Freezers, $n=5$ ) and sensitive (Bad Freezers, $n=6$ ) to freezing, and their MALDI-MS data were then compared. The Good Freezers group showed a higher abundance of phosphatidylcholines $(\mathrm{m} / \mathrm{z}$ 796.6, 846.6, 810.6, 854.6 and 732.6). The ions of $m / z 812.6,832.6,836.6$ and 838.6 belonging to the phosphatidylcholine lipid class were also positively correlated with motility of spermatozoa, whereas that of $m / z 794.6$ was negatively correlated with lipid peroxidation in thawed semen. The Bad Freezer group, displayed higher abundance of one phosphatidylcholines $(\mathrm{m} / \mathrm{z}$ 806.6), as well as a sphingomyelins $(\mathrm{m} / \mathrm{z}$ 703.5), which were negatively correlated (univariate analysis) with kinetics of spermatozoa after thawing $(\mathrm{m} / \mathrm{z} 703.5)$ and with membrane integrity $(\mathrm{m} / \mathrm{z} 792.6)$. The ion of $\mathrm{m} / \mathrm{z} 717.5$, assigned to phosphatidic acid, was negatively correlated with lipid peroxidation. In general therefore, the phosphatidylcholines are associated with higher quality of spermatozoa after thawing, especially in functional capacity, and that lipid semen composition was found to influence the resistance of spermatozoa to cryopreservation and may interfere with motility, membrane integrity and lipid peroxidation in stallions.
\end{abstract}

(c) 2017 Elsevier Inc. All rights reserved.

\section{Introduction}

Equine spermatozoa present greater sensitivity than other domestic species to the cryopreservation process, and individual variations are also expressed [1,2]. A possible explanation for this phenomenon is variations in the membrane lipid composition of spermatozoa, whose bi-dimensional lipid layer organization is known to be altered during freezing [3].

\footnotetext{
* Corresponding author. Departamento de Reprodução Animal e Radiologia Veterinária, FMVZ, Universidade Estadual Paulista, UNESP, Rua Prof. Doutor Walter Mauricio Correa, s/n, Unesp Campus de Botucatu, 18618-681, Botucatu, SP, Brazil.

E-mail address: fafesouza@fmvz.unesp.br (F.F. Souza).
}

The lipid membrane composition of the spermatozoa has been investigated in several species, such as swine [4,5], bulls [4], birds $[4,6]$, horses [4,7], mice [8] and humans [9] and has been characterized by a variety of phospholipids and polyunsaturated fatty acids (PUFAs) [7,10], which are necessary to maintain cellular structure, membrane fluidity and functionality of spermatozoa $[11,12]$.

Simpson et al. [13] reported that plasma membranes of spermatozoa in boars have a significant amount of phosphatidylcholines, which is involved in the highest level of cryoresistance. Plasminogen combined with PUFAs, which provides antioxidant properties to the membrane [6,14], has also been associated with motility, concentration, morphology and viability of spermatozoa 
[15]. The increased variability in lipid concentrations between individuals of the same species [16] may therefore be associated with the ability of spermatozoa to survive the freezing process.

Although several techniques are able to analyze the functional capacity of spermatozoa, still few studies have been reported about the correlation between the seminal lipids and the thawed characteristics of spermatozoa of stallions, which could allow a better understanding of the events that regulate fertilization capacity. The present study aims therefore to relate the lipid composition of the stallion's semen with quality after freezing of spermatozoa.

\section{Materials and methods}

\subsection{Ethical aspects, animals and groups}

The study was conducted in accordance with the ethical guidelines recommended by the National Council for the Control of Animal Experimentation and the College of Animal Experimentation and was approved by the Institutional Animal Care and Experimentation Ethics Committee (Protocol Number 162/2016).

Thirty-four healthy stallions were used, aged between 7 and 15 years. The animals were housed in the Breeding Center and had proven fertility ( $>50 \%$ pregnancy rate using fresh semen in the breeding season). All the semen samples were collected during the breeding season.

The stallions were selected according to the cryoresistance of their spermatozoa and placed into two groups: Good Freezers (resistant to cryopreservation) with $\geq 75 \%$ upper quartile to total ( $\geq 52.3 \%$ ) and progressive motility ( $\geq 21.3 \%$ ) and a rapid percentage of spermatozoa ( $\geq 35.3 \%$ ); and Bad Freezers (sensitive to cryopreservation), with $\leq 25 \%$ lower quartile to total $(\leq 37.5 \%)$ and progressive motility $(\leq 12.0 \%)$ and a rapid percentage of spermatozoa $(\leq 20.5 \%)$ after thawing.

\subsection{Semen collection and processing}

The semen was collected using an artificial vagina (Botupharma, Botucatu, SP, Brazil), and the gel fraction was removed using a nylon filter. The concentration of spermatozoa was determined in a Neubauer chamber and the semen was diluted in a skim milk-based extender (Botu-sêmen ${ }^{\circledR}$, Botupharma, Botucatu, SP, Brazil). Then, the samples were centrifuged at $600 \mathrm{~g}$ for $10 \mathrm{~min} \mathrm{[17],} \mathrm{and} \mathrm{the}$ spermatozoa were re-suspended in an egg yolk-based commercial extender (Botucrio ${ }^{\circledR}$, Botupharma, Botucatu, SP, Brazil) to a final concentration of $200 \times 10^{6}$ spermatozoa $/ \mathrm{mL}$. The samples were packed into $0.5 \mathrm{~mL}$ straws, maintained at $5{ }^{\circ} \mathrm{C}$ for $20 \mathrm{~min}$ (Minitub ${ }^{\circledR}$, Tiefenbach, Germany) and placed $6 \mathrm{~cm}$ above liquid nitrogen for another $20 \mathrm{~min}$. Straws were immersed in liquid nitrogen and stored at $-196{ }^{\circ} \mathrm{C}[18]$. The straws were thawed at $37^{\circ} \mathrm{C}$ for $30 \mathrm{~s}$, and the characteristics of spermatozoa reevaluated.

\subsection{Kinetics of spermatozoa}

Kinetics of spermatozoa was assessed using the computerassisted sperm analysis - CASA system (IVOS-12 Sperm Analyzer, Hamilton Thorne Biosciences Inc., Beverly, MA, USA). CASA system setups were from the Center for Study of Animal Reproduction (CERAN, FMVZ, UNESP, Botucatu, Brazil) and included image capture (frames per sec: $60 \mathrm{~Hz}$ ), image capture (No. of frames: 30 ), cell detection (min contrast: 30 ), cell detection (min cell size: 30 pixels), defaults (cell size: 5 pixels), defaults (cell intensity: 40), progressive cells (VAP: $70.0 \mu / \mathrm{s}$ ), progressive cells (STR: $80.0 \%$ ), slow cells (static, VAP cutoff: $30 \mu / \mathrm{s}$ ), slow cells (static, VSL cutoff: $20 \mu / \mathrm{s}$ ), illumination/intensity (3,600), illumination/photometer (125), video source (dark field: $60 \mathrm{~Hz}$ ), static intensity gates (min and max: 0.48 and 1.45), static elongation gates (min and max: 0 and 97), chamber type (Makler, chamber depth $10.0 \mu \mathrm{m}$, stage position $14.3 \mathrm{~mm}$, Hamilton Thorne Research, Beverly, MA, USA), temperature $\left(38^{\circ} \mathrm{C}\right)$ and automatic field selection.

The total (TM, \%) and progressive motility (PM, \%), average path velocity (VAP, $\mu \mathrm{m} / \mathrm{s}$ ), straight-line velocity (VSL, $\mu \mathrm{m} / \mathrm{s}$ ), curvilinear velocity (VCL, $\mu \mathrm{m} / \mathrm{s}$ ), oscillation coefficient (WOB) and rapid percentage of spermatozoa (RAP, \%) were evaluated in fresh and frozen/thawed samples.

\subsection{Flow cytometry}

The spermatozoa were evaluated by flow cytometry using the BD LSR Fortessa (Becton Dickinson, Mountain View, CA, USA) equipped with excitation lasers (blue $488-\mathrm{nm}, 100 \mathrm{~mW}$ and emission filters 530/30 nm and 695/40 nm; red $640 \mathrm{~nm}, 40 \mathrm{~mW}$ with emission filter $660 / 20 \mathrm{~nm}$; and violet $405-\mathrm{nm}, 100 \mathrm{~mW}$, with the emission filter $450 / 50 \mathrm{~nm}$ ). At least 10,000 cells per sample were analyzed and the data evaluated by BD software FACSDiva ${ }^{\mathrm{TM}}$ software v. 6.1

A semen aliquot diluted in TALP-PVA (according to Parrish et al. [19] modified: $100 \mathrm{mmol} / \mathrm{L} \mathrm{NaCl}, 3.1 \mathrm{mmol} / \mathrm{L} \mathrm{KCl}, 25.0 \mathrm{mmol} / \mathrm{L}$ $\mathrm{NaHCO}_{3}, 0.3 \mathrm{mmol} / \mathrm{L} \mathrm{NaH} \mathrm{PO}_{4}, 21.6 \mathrm{mmol} / \mathrm{L}$ DL-sodium lactate, $2.0 \mathrm{mmol} / \mathrm{L} \mathrm{CaCl}_{2}, 0.4 \mathrm{mmol} / \mathrm{L} \mathrm{MgCl}_{2}, 10.0 \mathrm{mmol} / \mathrm{L}$ Hepes - BSA free, $1.0 \mu \mathrm{g} / \mathrm{mL}$ polyvinyl alcohol-PVA and $25 \mu \mathrm{g} / \mathrm{mL}$ gentamicin) containing $5 \times 10^{6}$ spermatozoa/mL was added to a $70 \mathrm{nmol} / \mathrm{L}$ aqueous solution of Hoechst 33342 (code 14533, Sigma-Aldrich Co., St Louis, MO, USA) to identify cell events, excluding cellular debris. Then, $15 \mathrm{nmol} / \mathrm{L}$ propidium iodide (PI, P4170, Sigma-Aldrich Co., St Louis, MO, USA) was also added for the identification of cells with plasma membrane damage. Cells with membrane intact (MI) were PI negative. Lipid peroxidation was evaluated according to Guasti et al. [20] by adding $1 \mathrm{nmol} / \mathrm{L}$ C11-BODiPY (D-3861; Thermo Fisher Scientific, Waltham, MA, USA) diluted in DMSO. The cells with lipid peroxidation (PERO) were considered positive for C11-BODiPY. Samples were incubated in a water bath at $37{ }^{\circ} \mathrm{C}$ for $30 \mathrm{~min}$ and then washed in TALP-PVA twice at $300 \mathrm{~g}$ for $5 \mathrm{~min}$, re-suspended and evaluated by flow cytometry.

\subsection{Lipid analysis by MALDI-MS}

Samples containing $50 \times 10^{6}$ fresh spermatozoa (in natura) were stored at $-196{ }^{\circ} \mathrm{C}$ for lipidomic analysis. Samples were subjected to liquid-liquid extraction of the total lipids following the protocol described by Bligh and Dyer [21], with modifications. An aliquot was thawed at room temperature, re-suspended in $1 \mathrm{~mL}$ of saline phosphate buffer (PBS) and homogenized for $3 \mathrm{~min}$. The sample was centrifuged at $12,000 \mathrm{~g}$ for $1 \mathrm{~min}$ at room temperature. Then, the supernatant was discarded and the procedure was repeated once more. Next, $500 \mu \mathrm{L}$ of a chloroform-methanol solvent mixture $(1: 2 \mathrm{v} / \mathrm{v})$ and $150 \mu \mathrm{L}$ of distilled water were added to the sediment, and the tubes were then shaken vigorously for $2 \mathrm{~min}$. Afterwards, the sample was re-centrifuged at $5000 \mathrm{~g}$ for $3 \mathrm{~min}$ at room temperature. The aqueous supernatant was discarded and the organic phase (lower phase) was collected, dried for $60 \mathrm{~min}$ in a concentrator and stored at $-196{ }^{\circ} \mathrm{C}$.

Samples were re-suspended in $50 \mu \mathrm{L}$ of a mixture of methanolchloroform (1:2 v/v) for MALDI-MS analysis. Each extract sample $(1 \mu \mathrm{L})$ was deposited on a spot on the MALDI target plate, allowed to dry at room temperature and covered with the matrix solution ( $1 \mu \mathrm{L}$ of 2.5 -dihydroxybenzoic acid, DHB, $30 \mathrm{mg} / \mathrm{mL}$ in methanol). MALDI data were acquired using an Autoflex III MALDI time-offlight (TOF) mass spectrometer operated in the reflectron mode and equipped with smartbeam ${ }^{\mathrm{TM}}$ laser technology (Bruker Daltonics, Bremen, Germany). The MS data were acquired in the 
positive ion mode and in the $m / z$ (mass-to-charge ratio) 700-1000 range, averaging 1000 consecutive laser shots and a frequency of $200 \mathrm{~Hz}$. Raw mass spectra were processed using FlexAnalysis Software (version 3.0, Bruker Daltonics, Bremen, Germany) and submitted to multivariate analysis.

Lipid subclasses were attributed by comparison with literature data [9,22-28] and/or in databases (http://www.hmdb.ca and http://www.lipidmaps.org). The error mass calculation is directly connected with mass accuracy, which enables the assured identification of molecules using the $m / z$ values of the ions detected in the mass spectrum.

\subsection{Data analysis}

The kinetics and flow cytometry variables of all samples were described by the median, minimum, maximum, 25\% and 75\% quartiles, mean, standard deviation and standard error. The variable comparisons were performed by $t$-test (parametric variables) or Mann-Whitney (non-parametric variables) based on Kolmogorov-Smirnov test (K-S) results, which checked distribution.

For lipidomic analysis, the data normalization was performed to remove ions that were present in less than three animals (Good Freezers and Bad Freezers). The normalization (log normalization) was conducted to adjust the differences between samples and make the variables more comparable in order to obtain better results. Thus, the data became more homogeneous and the analysis more accurate.

The multivariate statistical analysis of MALDI-MS data was performed in MetaboAnalyst 3.0 online free software [29]. The groups were non-hierarchically clustered, with the samples divided into a predetermined number of groups [30]. The principal component analysis (PCA), in which the variable series is defined as a principal component, was used for the description of sample variation, determining the accuracy of group's division, and preserving the more relevant divisions. The partial least squares-discriminant analysis (PLS-DA) is a chemometric method that was used to assign samples according to classes, indicating a ranking and calculating variables' importance on projection score (VIP score). The VIP score was considered as $\alpha \geq 1$ [30]. The relative abundance (relative intensity, which is the amount of an ion produced in relation to the amount of the most abundant ion) of lipid species between Good Freezers and Bad Freezers groups was identified using a $t$-test.

The correlation of the lipids, flow cytometry and kinetics variables was analyzed by the Pearson correlation test. The correlation coefficient was classified as null $(r=0)$, low $(0<r \leq 0.30)$, moderate $(0.30<\mathrm{r} \leq 0.70)$ and strong $(0.7<\mathrm{r} \leq 1)$ according to Levine et al. [31]. These analyses were performed by the GraphPad Prism version 6.0 for Windows program (GraphPad software, LA Jolla, California, USA; http://www.graphpad.com). A P value of $\leq 0.05$ was considered statistically significant.

\section{Results}

From 34 stallions studied, 11 were classified as Good Freezers $(n=5)$ or Bad Freezers $(n=6)$ : other males were of median cryoresistance and were not included in the multivariate analysis. Fresh spermatozoa characteristics were obviously greater than thawed samples (Table S1) in all the stallions $(\mathrm{n}=34)$.

Fig. 1 shows representative MALDI-MS data for each experimental group (Good and Bad Freezers). The lipid profiles of the spermatozoa were characterized by the major ions of $m / z 700.6$ to 854.6 .

Subsequently, MALDI-MS data were explored by multivariate analysis to investigate differences between the Good Freezers and
Bad Freezers groups. First, a multivariate exploratory regression was used, based on the principal component analysis (PCA), to verify responsibility for the greater variance between the data. In this type of analysis, the samples are grouped according to prior information about the groups, only using the instrumental data provided (Fig. 2A). The data set was also submitted for partial least squares discriminant analysis (PLS-DA). This method of analysis identifies specific similarities or differences through the organization of major components that are correlated with variables of interest in this case, the Good Freezers and Bad Freezers groups. As expected, the same trend of separation between different groups and the grouping of similar samples was observed in the plot (Fig. 2B). In Fig. 2C, the VIP plot shows the ions responsible for the discrimination of the experimental groups in the PLS-DA model. Table 1 reports the tentative assignments of the VIP ions.

The PLS-DA (Fig. 2C) indicated 10 ions correlated with cryoresistance in Good Freezers and Bad Freezers groups, of which 6 of those ions were found in lower abundance in the Bad Freezers $(\mathrm{m} / \mathrm{z}$ 727, 732.6, 796.6, 810.6, 846.6 and 854.6) and higher abundance in the Good Freezers. Although the VIP score threshold has been fixed as $\geq 1(\alpha \geq 1)$, we found a range $0.0-0.5$, which indicates that the main ions were those closer to $1(\mathrm{~m} / z 846.6$ and 796.6). Nevertheless, from a list of all ions, we can determine, through the PLSDA, at least $5(\alpha>0.3)$ that the ions of $m / z$ 846.6, 796.6, 727.0, 810.6 and 854.6 are the most relevant ones.

The MALDI-MS data were also correlated with characteristics of fresh and thawed spermatozoa (Table 2 and Table S2). The ions of $m / z$ 703.5, 725.5, 812.6, 832.6, 836.6 and 838.6 have been highlighted as primary in this study since they correlated with several characteristics of fresh and frozen semen. Interestingly, the ions of $m / z$ 832.6, 836.6 and 838.6 were only correlated with the characteristics of thawed sperm. The ions of $m / z 717.5$ and 794.6 were negatively correlated with lipid peroxidation. Similar results were also observed with the ions of $m / z 781.5$ (fresh semen) and 792.6 (thawed semen) that negatively correlated with membrane integrity.

\section{Discussion}

The process of freezing semen induces significant biophysical and biochemical changes in the spermatozoa, including modifications of membranes and their components. Because of this changes, lipid composition of the sperm membrane constitutes an important factor in cryopreservation since its membrane integrity is altered during this process $[13,33]$. In the present study, we investigated the relationship between the lipids of the semen and the postthawing sperm characteristics of stallions.

From 34 stallions studied, 14.7\% were classified as Good Freezers and $17.6 \%$ as Bad Freezers, which indicates that $70 \%$ of males used in our study had medium seminal characteristics. This result is similar to previous studies, which reported that approximately $60 \%$ of stallions produce semen that can accept the freezing process (medium), whereas $20 \%$ freeze well and $20 \%$ present poor postfreezing quality [34]. The stallions that accept freezing or experience poor quality in their thawed semen also had reduced fertility, which can be related to selection genetics [35].

Animals classified as freezing-resistant (the Good Freezers group) had in general higher relative abundances of phosphatidylcholines, represented by ions of $m / z$ 732.6, 810.6, 846.6 and 854.6. In a study conducted by Lessig et al. [36], higher abundance of phosphatidylcholines was also found, followed by sphingomyelins in human and swine sperm membranes. Although phosphatidylcholines constitute the greater lipid fraction present in the cell membrane, at approximately $23.2 \%$ in equine spermatozoa [10], the high abundances of these phospholipids can also be due to a 


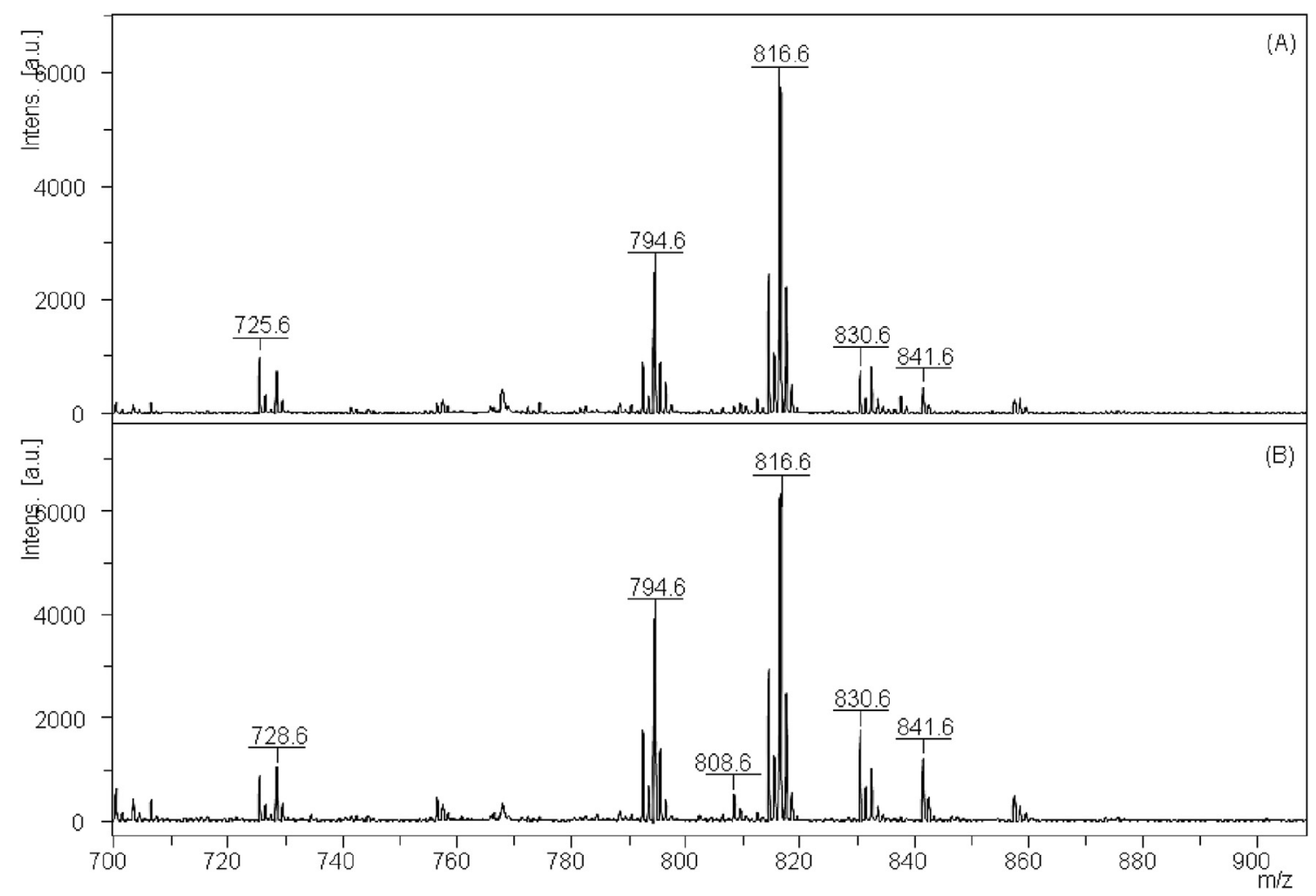

Fig. 1. Representative MALDI-MS of spermatozoa from Good Freezer (A) and Bad Freezer (B) groups.

permanent positive charge in this lipid class with quaternary ammonia groups [24] since MALDI-MS was conducted in the positive ion mode.

A positive correlation between phosphatidylcholines abundance $(m / z$ 812.6, 832.6, 836.6 and 838.6) and the sperm motility in thawed spermatozoa was also noted. These results were similar to those reported by Simpson et al. [13], in which the addition of phosphatidylcholine to the extender prevented epididymal sperm from suffering structural damage induced by cold shock and maintained motility and oxygen consumption similar to ejaculated boar spermatozoa, making them more resistant to cold shock than those from the epididymis.

Spermatozoa are subjected to several injuries during cryopreservation, and it is possible to presume that the phosphatidylcholine content in the sperm membrane is modified during this process, which can compromise sperm function, particularly since the phospholipids are associated with the acrosome reaction in humans [37]. During ejaculation, there is also an interaction between choline residues of membrane phospholipids with equine seminal plasma proteins (HSP1-2), which seems to stimulate the efflux of cholesterol and phospholipids through molecules such as heparin involved in sperm capacitation $[38,39]$. Alterations in the membrane lipid composition could impair this process.

The phosphatidylcholines plasmalogens represented by the ions of $m / z 796.6$ [23] and $m / z 794.6$ [28] showed a higher relative abundance in animals from the Good Freezers group and were

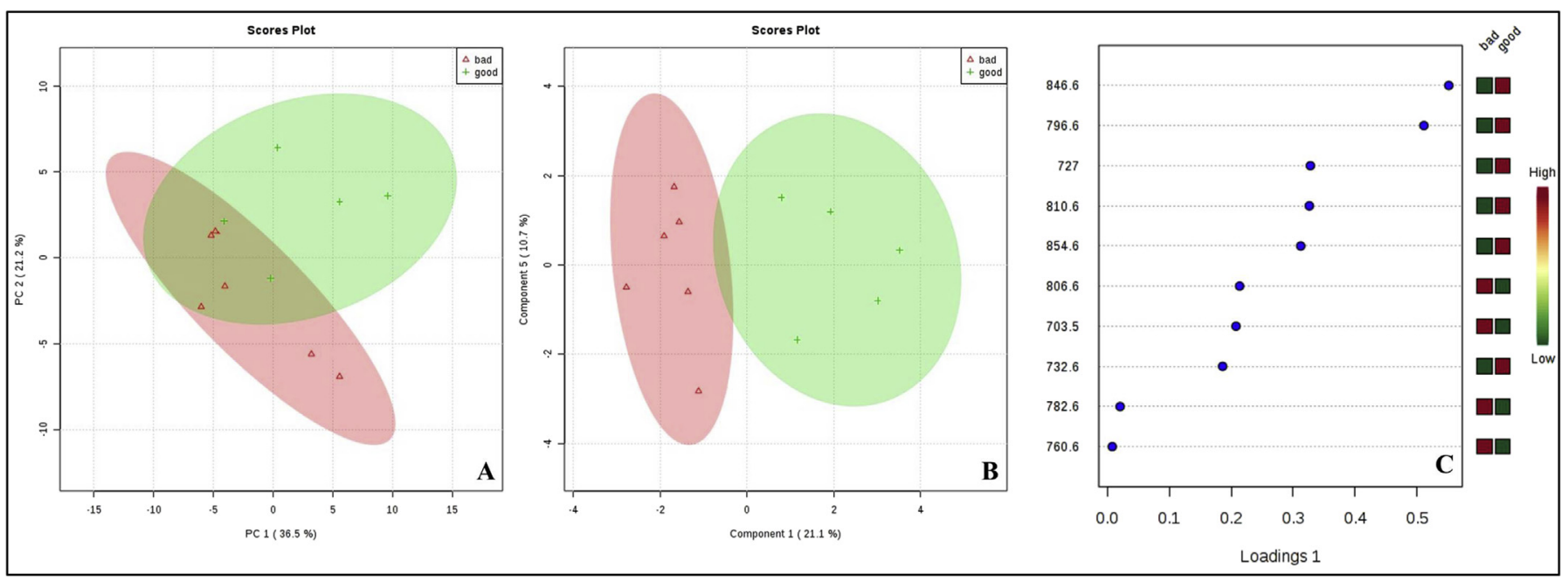

Fig. 2. A PCA (A) and PLS-DA (B) plot of the MALDI-MS data obtained from spermatozoa. (C) A VIP plot highlighting the ions responsible for the PLS-DA discrimination. 
Table 1

Spermatozoa phospholipids responsible for the discrimination between Good Freezers and Bad Freezers groups by in multivariate analysis identified for MALDI-MS.

\begin{tabular}{lll}
\hline$m / z$ & Lipid ion $(\mathrm{CN}: \mathrm{DB})^{\mathrm{a}}$ & \\
\hline 703.5 & {$[\mathrm{SM}(16: 0)+\mathrm{H}]^{+}$} & Reference \\
727.0 & Not identified & {$[9,23,25]$} \\
732.6 & {$[\mathrm{PC}(32: 1)+\mathrm{H}]^{+}$} & $*$ \\
760.6 & {$[\mathrm{PC}(34: 1)+\mathrm{H}]^{+}$} & {$[22]$} \\
782.6 & {$[\mathrm{PC}(36: 4)+\mathrm{H}]^{+}$} & {$[9,28]$} \\
796.6 & $\mathrm{PC}(37: 4)+\mathrm{H}]$ and $/$ or $[\mathrm{PCp}(38: 3)+\mathrm{H}]^{+}$and $/$or $[\mathrm{PCe}(38: 4)+\mathrm{H}]^{+}$ & {$[22]$} \\
806.6 & {$[\mathrm{PC}(38: 6)+\mathrm{H}]^{+}$} & {$[22,23]$} \\
810.6 & {$[\mathrm{PC}(38: 4)+\mathrm{H}]^{+}$} & {$[22]$} \\
846.6 & {$[\mathrm{PC}(40: 0)+\mathrm{H}]^{+}$} & {$[22]$} \\
854.6 & {$[\mathrm{PC}(42: 10)+\mathrm{H}]^{+}$} & {$[23]$} \\
\hline
\end{tabular}

Identification based in lipid databases (http://www.lipidmaps.org and http://www.hmdb.ca) and early studies [9,22,23,25,27,28].

*Ions not identified in the databases.

a CN:DB, carbon number/double bound; PC, phosphatidylcholine; PA phosphatidic acid; SM sphingomyelin; PE phosphatidylethanolamine;

TAG triacylglycerol; PC with e and/or p refers to the subspecies plasmanyl e plasmenyl, respectively.

negatively correlated with lipid peroxidation in thawed semen. Note that plasmalogens are characterized by an ether linkage at carbon 1 or 2 of the glycerol molecule and are generally combined with PUFAs, mainly docosahexanoic acid and docosapentanoic acid $[40,41]$, and have been associated with cellular protection against oxidative stress [42]. It is possible therefore that the greater relative abundance of this lipid class in the animals of the Good Freezers group is associated with a decrease in oxidative stress, improving the spermatozoa characteristics post-cryopreservation. The PUFAs are also directly related to the fusion of the oocyte and to fertilizing capacity. In stallions, the addition of docosahexaenoic acid (22: 6 n3 ) in the diet showed improvement in the quality of cell characteristics in cooled and frozen/thawed semen $[43,44]$.

The higher abundance of sphingomyelin represented by the ion of $m / z 703.5$ present in the Bad Freezers and their negative correlation with sperm motility after thawing can be attributed to the absence of double bond fatty acids in their molecular structure. The relationship of these lipids with lower membrane integrity is possibly due to the presence of saturated fatty acids in the molecular structure, which is associated with higher membrane stiffness $[12,45]$. Sphingomyelins have also been associated with the induction of apoptosis and generation of ceramides [46,47].

According to Post et al. [48], when membrane destabilization occurs, phosphatidylethanolamines are redistributed and exposed to the cellular environment, signaling cell death. It is plausible therefore that the greater abundance of this lipid in the Bad Freezers group and its negative correlation with membrane integrity (represented by the ion of $m / z 792.6$ ) is associated with a possible apoptosis process in the post-thawed spermatozoa.

Phosphatidic acid plays a key role in lipid metabolism since it is an essential substrate for the enzymes involved in glycerophospholipid and triacylglycerol biosynthesis [49] and is associated with cell signaling and membrane transport. Its negative correlation (represented by ion of $m / z$ 717.5) with the lipid peroxidation seems to suggest therefore that this lipid may be related to increased sperm resistance to the cryopreservation process. In rats, it has been shown that its acid phosphatidic enzyme, phospholipase $\mathrm{A} 1$, apparently regulates the organization of mitochondria during spermatogenesis, in which its deficiency causes loss of sperm motility due to flagella modification and high levels generate defects in formation of spermatozoa [50].

In summary, phosphatidylcholines and plasmalogens were associated with improved characteristics in thawed spermatozoa. Further studies on the lipid composition of semen should therefore be conducted to allow the characterization of seminal quality and its potential use as a fertility biomarker. Our results also motivates studies that would provide insight into the supplementation of lipid components to semen or feeding media in order to make the spermatozoa more resistant to the cryopreservation process.

Table 2

Spermatozoa phospholipids responsible for the discrimination between Good Freezers and Bad Freezers groups by in univariate analysis via MALDI-MS.

\begin{tabular}{|c|c|c|}
\hline$m / z$ & Lipid ion $(\mathrm{CN}: \mathrm{DB})^{\mathrm{a}}$ & Reference \\
\hline 700.6 & {$[\mathrm{PC}(30: 3)+\mathrm{H}]^{+}$} & {$[23]$} \\
\hline 703.5 & {$[\mathrm{SM}(16: 0)+\mathrm{H}]^{+}$} & {$[23,25]$} \\
\hline 717.5 & {$[\mathrm{PA}(36: 5)+2 \mathrm{H}+\mathrm{Na}]^{+}$} & {$[24]$} \\
\hline 725.5 & {$[\mathrm{SM}(16: 0)+\mathrm{Na}]^{+}$} & {$[23,25,26]$} \\
\hline 728.6 & {$[\mathrm{PC}(32: 3)+\mathrm{H}]^{+},[\operatorname{PEp}(36: 2)+\mathrm{H}]^{+},[\operatorname{PEe}(36: 3)+\mathrm{H}]^{+}$} & [23] \\
\hline 748.6 & {$[\mathrm{PCe}(34: 0)+\mathrm{H}]$} & [32] \\
\hline 760.6 & PE (18:0/20:0) & * \\
\hline 781.5 & Not identified & * \\
\hline 792.6 & [1-palmityl-2-docosahexaenoyl-GPC $+\mathrm{H}]^{+}$ & [28] \\
\hline 794.6 & $[\mathrm{PE}(40: 5)+\mathrm{H}]+,[\mathrm{PCp}(38: 4)+\mathrm{H}]^{+},[\mathrm{PCe}(38: 5)+\mathrm{H}]^{+}$and/or [1- palmityl-2-docosapentaenoyl- GPC $\left.+\mathrm{H}\right]^{+}$ & {$[23,28]$} \\
\hline 812.6 & $[\mathrm{PC}(38: 3)+\mathrm{H}]^{+}$and/or PS $\left.(38: 4)+\mathrm{H}\right]^{+}$and/or [1-palmitenyl-2- docosahexaenoyl- GPC $\left.+\mathrm{Na}\right]^{+}$ & {$[23,26,28]$} \\
\hline 828.0 & Not identified & $*$ \\
\hline 832.6 & {$[\mathrm{PC}(40: 7)+\mathrm{H}]^{+}$and/or $[\mathrm{PC}(38: 4)+\mathrm{Na}]^{+}$} & {$[22,25]$} \\
\hline 830.6 & {$[\mathrm{PCp}(40: 0)+\mathrm{H}]^{+},[\mathrm{PCe}(40: 1)+\mathrm{H}]^{+},[\mathrm{PC}(38: 5)+\mathrm{H}]^{+}$} & {$[23,28]$} \\
\hline 836.6 & {$[\mathrm{PC}(40: 5)+\mathrm{H}]^{+}$} & [22] \\
\hline 838.6 & {$[\mathrm{PC}(40: 4)+\mathrm{H}]^{+}$} & [23] \\
\hline
\end{tabular}

Identification based in lipid databases (http://www.lipidmaps.org and http://www.hmdb.ca) and early studies [22-26,28,32].

*Ions not identified in the databases.

a CN:DB, carbon number/double bound; PC, phosphatidylcholine; PA phosphatidic acid; SM sphingomyelin; PE phosphatidylethanolamine; TAG triacylglycerol; PC with "e" and/or "p" refers to the subspecies plasmanyl e plasmenyl, respectively. 


\section{Acknowledgments}

This research was supported by the São Paulo Research Foundation (Fundação de Amparo à Pesquisa do Estado de São PauloFAPESP, number 13/12.838-9) and Coordination of Improvement of Higher Education Personnel (Coordenação de Aperfeiçoamento Pessoal de Nível Superior- CAPES) by granting the scholarship. We also thank Dra. Thaís Regiani Cataldi, Department of Genetic, ESALQ University of São Paulo, SP, Brazil who helped us to better understand the lipidomics and for her assistance in statistical analysis.

\section{Appendix A. Supplementary data}

Supplementary data related to this article can be found at https://doi.org/10.1016/j.theriogenology.2017.11.025.

\section{References}

[1] Alvarenga MA, Papa FO, Landim-Alvarenga FC, Medeiros AS. Amides as cryoprotectants for freezing stallion semen: a review. Anim Reprod Sci 2005;89: 105-13.

[2] Vidament M. French field results (1985-2005) on factors affecting fertility of frozen stallion semen. Anim Reprod Sci 2005;89:115-36.

[3] Holt WV. Fundamental aspects of sperm cryobiology: the importance of species and individual differences. Theriogenology 2000;53:47-58.

[4] Parks JE, Lynch DV. Lipid composition and thermotropic phase behavior of boar, bull, stallion, and rooster sperm membrane. Cryobiology 1992;29: 255-66.

[5] Am-In N, Kirkwood RN, Tecchakumphu M, Tantasuparuk W. Lipids profiles of sperm and seminal plasma from boars having normal or low sperm motility. Theriogenology 2011;75:897-903.

[6] Cerolini S, Keslo KA, Noble RC, Speake BK, Pizzi F, Cavalchini LG. Relationship between spermatozoa lipid composition and fertility during aging of chickens. Biol Reprod 1997;57:976-80.

[7] Wood PL, Scoggin K, Ball BA, Troedsson MH, Squires EL. Lipidomics of equine sperm and seminal plasma: identification of amphiphilic (O-acyl)- $\omega$-hydroxyfatty acids. Theriogenology 2016;86:1212-21.

[8] Naoko-Goto-Inoue N, Hayasaka T, Zaima N, Setou M. The specific localization of seminolipid molecular species on mouse testis during testicular maturation revealed by imaging mass spectrometry. Glycobiology 2009;19:950-7.

[9] Schiller J, Arnhold J, Glander HJ, Arnold K. Lipids analysis of human spermatozoa and seminal plasma by MALDI-TOF mass spectrometry and NMR spectroscopy - effects of freezing and thawing. Chem Phys Lipids 2000;106: $145-56$.

[10] Gadella BM, Rathi R, Bevers MM, Brouwers JFHM, Neild D, Colenbrander B, et al. The role of lipid dynamics in equine sperm plasma membrane function. Havemeyer Found Monogr Ser 2001;5:24.

[11] Hammerstedt RH, Graham JK, Nolan JP. Cryopreservation of mammalian sperm: what we ask them to survive. J Androl 1990;11:73-88.

[12] Flesch FM, Gadella BM. Dynamics of the mammalian sperm plasma membrane in the process of fertilization. Biochim Biophys Acta 2000;1469:197-235.

[13] Simpson AM, Swan MA, White IG. Susceptibility of epididymal boar sperm to cold chock and protective action of phosphatidiylcholine. Gamete Res 1987; $17: 355-73$.

[14] Gorgas K, Teigler A, Komljenovic D, Just WW. The ether lipid-deficient mouse: tracking down plasmalogen functions. Biochim Biophys Acta 2006;1763: 1511-26.

[15] Aksoy Y, Aksoy H, Altinkaynak K, Aydin HR, Özkan A. Sperm fatty acid composition in subfertile men. Prostagl Luekot Essent Fat Acids 2006;75: 75-9.

[16] Zalata AA, Christophe AB, Depuydt E, Schoonjans F, Comhaire FH. The fatty acid composition of phospholipids of spermatozoa from infertile patients. Mol Hum Reprod 1998;4:111-8.

[17] Dell'Aqua JA, Papa FO, Alvarenga MA, Zahn FS. Effect of centrifugation an packing system on sperm parameters of equine frozen semen. Anim Reprod Sci 2001;68:324-5.

[18] Papa FO, Melo CM, Fioratti EG, Dell'aqua Jr JA, Zhan FS, Alvarenga MA. Freezing of stallion epididymal sperm. Anim Reprod Sci 2008;107:293-301.

[19] Parrish JJ, Susko-Parrish J, Winer MA, First NL. Capacitation of bovine sperm by heparin. Biol Reprod 1988;38:1171-80.

[20] Guasti PN, Freitas-Dell'aqua CP, Maziero RRD, Hartwig FP, Monteiro GA, Lisboa FP, et al. Validation of flow cytometry for assessment of membrane lipid peroxidation of equine spermatozoa. Anim Reprod 2012;9:929.

[21] Bligh EG, Dyer JW. A rapid method of total lipid extraction and purification. Biochim Can J Physiol 1959;37:911-7.

[22] Belaz KR, Tata A, França MR, Santos da Silva MI, Vendramini PH, Fernandes AM, et al. Phospholipid profile and distribution in the receptive oviduct and uterus during early diestrus in cattle. Biol Reprod 2016;95(6):
$1-11$.

[23] Milne S, Ivanova P, Forrester J, Brown HA. Lipidomics: an analysis of cellular lipids by ESI-MS. Methods 2006;39:92-103.

[24] Petkovic M, Schiller J, Muller M, Bernard S, Reichl S, Arnold K, et al. Detection of individual phospholipids in lipid mixtures by matrix-assisted lase desorption/ionization time-of-flight mass spectrometry: phophatidylcholine prevents the detection of further species. Anal Biochem 2001;289:202-6.

[25] Ferreira CR, Saraiva AS, Catharino RR, Garcia JS, Gozzo FC, Sanvido GB, et al Single embryo and oocyte lipid fingerprinting by mass spectrometry. J Lipid Res 2010;51:1218-27.

[26] Brugger B, Erben G, Sandhoff R, Wieland FT, Lehmann WD. Quantitative analysis of biological membrane lipids at the low picomole level by nanoelectrospray ionization tandem mass spectrometry. Proc Natl Acad Sci U. S. A 1997;94:2339-44.

[27] Roy MC, Nakanishi H, Takahashi K, Nakanishi S, Kajihara S, Hayasaka T, et al Salamander retina phospholipid and their localization by MALDI imaging mass spectrometry at cellular size resolution. J Lipid Res 2011;52:463-70.

[28] Fuchs B, Jakop U, Göritz F, Hermes R, Hildebrandt T, Schiller J, et al. MALDITOF "fingerprint" phospholipid mass spectra allow the differentiation between ruminantia and feloideae spermatozoa. Theriogenology 2009;71: $568-75$.

[29] Xia J, Wishart DS. Using MetaboAnalyst 3.0 for comprehensive metabolomics data analysis. Curr Protoc Bioinforma 2016;55. 14.10.1-91.

[30] Checa A, Bedia C, Jaumot J. Lipidomic data analysis: tutorial, practical guidelines and applications. Anal Chim Acta 2015;885:1-16.

[31] Levine DM, Stephan DF, Krehbiel TC, Berenson ML. Estatística: teoria e aplicacões. sixth ed. Rio de Janeiro: LTC; 2013.

[32] Tata A, Sudano MJ, Santos VG, Landim-Alvarenga FD, Ferreira CR, Eberlin MN. Optimal single-embryo mass spectrometry fingerprinting. J Mass Spectrom 2013;48:844-9.

[33] Pettit MJ, Buhr MM. Extender components and surfactants affect boar sperm function and membrane behaviour during cryopreservation. J Andro 1998; 19:736-46.

[34] Vidament M, Dupere AM, Julienne P, Evain A, Noue P, Palmer E. Equine frozen semen: freezability and fertility field results. Theriogenology 1997;48(3-4): 907-17.

[35] Sieme H, Harrison RAP, Petrunkina AM. Cryobiological determinants of frozen semen quality, with special reference to stallion. Anim Reprod Sci 2008;107: 276-92.

[36] Lessig J, Gey C, Suß R, Schiller J, Glander HJ, Arnhold J. Analysis of the lipid composition of human and boar spermatozoa by MALDI-TOF mass spectrometry, thin layer chromatography and 31P NMR spectroscopy. Comp Biochem Physiol B 2004;137:265-77.

[37] Cross NL. Phosphatidylcoline enhances the acrosomal responsiveness of human sperm. J Androl 1994:15:484-8.

[38] Ekhlasi-Hundrieser M, Schäfer B, Kirchhoff C, Hess O, Bellair S, Müller P, et al Structural and molecular characterization of equine sperm-binding fibronectin-II module proteins. Mol Reprod Dev 2005;70:45-57.

[39] Manjunath P, Thérien I. Role of seminal plasma phospholipid-binding proteins in sperm membrane lipid modification that occurs during capacitation. J Reprod Immunol 2002;53:109-19.

[40] Nagan N, Zoeller RA. Plasmalogens: biosynthesis and functions. Prog Lipid Res 2001;40:199-229.

[41] García BM, Fernandez LG, Ferrusola CO, Bolanos JMG, Martinez HR, Tapia JA et al. Fatty acids and plasmalogens of the phospholipids of the sperm membranes and their relation with the post-thaw quality of stallion spermatozoa. Theriogenology 2011;75:811-8.

[42] Khaselev N, Murphy R. Structural characterization of oxidized phospholipid products derived from arachidonate-containing plasmenyl glycerophosphocholine. J Lipid Res 2000;41:564-72.

[43] Brinsko SP, Varner DD, Love CC, Blanchard TL, Day BC, Wilson ME. Effect of feeding a DHA-enriched nutriceutical on the quality of fresh, cooled and frozen stallion semen. Theriogenology 2005;63:1519-27.

[44] Elhordoy DM, Cazales N, Costa G, Estevez J. Effect of dietary supplementation with DHA on the quality of fresh, cooled and frozen stallion semen. Anim Reprod Sci 2008;107:319.

[45] Lenzi A, Picardo M, Gandini L, Donodero F. Lipids of the sperm plasma membranes: from polyunsatured fatty acids considered as markers of sperm function to possible scavenger therapy. Hum Reprod Update 1996;2:246-56.

[46] Sudano MJ, Santos VG, Tata A, Ferreira CR, Paschoal DM, Machado R, et al. Phosphatidylcholine and sphingomyelin profiles vary in Bos taurus indicus and Bos Tauru Taurus in-vitro and in vivo-produced blastocysts. Biol Reprod 2012;87:1-11.

[47] Kalo D, Roth Z. Involvement of the sphingolipid ceramide in heat-shockinduced apoptosis of bovine oocytes. Reprod Fertil Dev 2011;23:876-88.

[48] Post JA, Bijvelt JJ, Aj V. Phosphatidylethanolamine and sarcolemal damage during ischemia or metabolic inhibition of heart myocytes. Am J Physiol 1995;268:H773-80.

[49] Athensthaedt K, Daum G. Phosphatidic acid, a key intermediate in lipid metabolism. Eur J Biochem 1999;266:1-16. /55.

[50] Baba T, Kashiwagi Y, Arimitsu N, Kogure T, Edo A, Maruyama T, et al. Phosphatidic acid (PA)-preferring phospholipase A1 regulates mitochondrial dynamics. J Biol Chem 2014;289:11497-511. $/ 56$. 